\title{
Copper-induced stimulation of nitrification in biological rapid sand filters for drinking water production by proliferation of Nitrosomonas spp.
}

\author{
Wagner, Florian Benedikt; Diwan, Vaibhav; Dechesne, Arnaud; Fowler, Jane; Smets, Barth F.; \\ Albrechtsen, Hans-Jørgen
}

\author{
Published in: \\ Environmental Science and Technology
}

Link to article, DOI:

10.1021/acs.est.9b03885

Publication date:

2019

Document Version

Peer reviewed version

Link back to DTU Orbit

Citation (APA):

Wagner, F. B., Diwan, V., Dechesne, A., Fowler, J., Smets, B. F., \& Albrechtsen, H-J. (2019). Copper-induced stimulation of nitrification in biological rapid sand filters for drinking water production by proliferation of Nitrosomonas spp. Environmental Science and Technology, 53(21), 12433-12441.

https://doi.org/10.1021/acs.est.9b03885

\section{General rights}

Copyright and moral rights for the publications made accessible in the public portal are retained by the authors and/or other copyright owners and it is a condition of accessing publications that users recognise and abide by the legal requirements associated with these rights.

- Users may download and print one copy of any publication from the public portal for the purpose of private study or research.

- You may not further distribute the material or use it for any profit-making activity or commercial gain

- You may freely distribute the URL identifying the publication in the public portal 


\section{Environmental Processes}

Subscriber access provided by DTU Library

\section{Copper-induced stimulation of nitrification in biological rapid sand filters for drinking water production by proliferation of Nitrosomonas spp.}

Florian B. Wagner, Vaibhav Diwan, Arnaud Dechesne, S.

Jane Fowler, Barth F. Smets, and Hans Jorgen Albrechtsen

Environ. Sci. Technol., Just Accepted Manuscript • DOI: 10.1021/acs.est.9b03885 • Publication Date (Web): 08 Oct 2019

Downloaded from pubs.acs.org on October 16, 2019

\section{Just Accepted}

"Just Accepted" manuscripts have been peer-reviewed and accepted for publication. They are posted online prior to technical editing, formatting for publication and author proofing. The American Chemical Society provides "Just Accepted" as a service to the research community to expedite the dissemination of scientific material as soon as possible after acceptance. "Just Accepted" manuscripts appear in full in PDF format accompanied by an HTML abstract. "Just Accepted" manuscripts have been fully peer reviewed, but should not be considered the official version of record. They are citable by the Digital Object Identifier (DOI@). "Just Accepted" is an optional service offered to authors. Therefore, the "Just Accepted" Web site may not include all articles that will be published in the journal. After a manuscript is technically edited and formatted, it will be removed from the "Just Accepted" Web site and published as an ASAP article. Note that technical editing may introduce minor changes to the manuscript text and/or graphics which could affect content, and all legal disclaimers and ethical guidelines that apply to the journal pertain. ACS cannot be held responsible for errors or consequences arising from the use of information contained in these "Just Accepted" manuscripts. 


\section{Copper-induced stimulation of nitrification in biological}

2 rapid sand filters for drinking water production by

3 proliferation of Nitrosomonas spp.

4 Florian B. Wagner*,+, ${ }^{*}$ Vaibhav Diwan ${ }^{+}$, Arnaud Dechesne, S. Jane Fowler, Barth F. Smets, Hans-

5 Jørgen Albrechtsen

6 Department of Environmental Engineering, Technical University of Denmark, Bygningstorvet Building

$7 \quad 115,2800$ Kgs. Lyngby, Denmark

8 * Corresponding author - email:fbw@kruger.dk

$9+$ These authors contributed equally

${ }^{1}$ Current address: Krüger A/S / Gladsaxevej 363 / 2860 Søborg / Denmark 


\section{ABSTRACT}

15 Copper is a co-factor of the ammonia monooxygenase, an essential enzyme for the activity of ammonia 16 oxidizing prokaryotes (AOP). Copper dosing at less than $1 \mu \mathrm{g} / \mathrm{L}$ stimulated ammonium removal in the 17 poorly-nitrifying biological filters of three full-scale drinking water treatment plants. Upon copper 18 dosing, the ammonium concentration in the effluent decreased from up to 0.18 to less than $0.01 \mathrm{mg} \mathrm{NH}_{4}^{+}-$

19 N/L. To investigate how copper dosing affected the filter microbial community, we applied amplicon 20 sequencing and qPCR targeting key nitrifying groups, including complete ammonia oxidizing 21 (comammox) Nitrospira. Copper dosing increased the abundance of different nitrifiers. Multiple 22 Nitrosomonas variants (betaproteobacterial ammonia oxidizers), which initially collectively represented $231 \%$ or less of the total community, increased almost 10 fold. Comammox Nitrospira were abundant and 24 increased too, but their relative abundance within the AOP decreased because of Nitrosomonas 25 proliferation. No other consistent change in the filter communities was detected, as well as no adverse 26 effect of copper on the filters functionality. Our results show that copper dosing in three independent 27 plants was associated with consistent growth of AOP and that efficient nitrification was achieved through 28 the joint contribution of comammox Nitrospira and an increasing fraction of betaproteobacterial 29 ammonia oxidizers. 


\section{GRAPHICAL ABSTRACT}

32 - Please see separate file -

\section{3}

34

35

36 
INTRODUCTION

When anaerobic groundwater is treated for drinking water production, biological granular media filters are commonly used to remove ammonium through nitrification after aeration. In this aerobic microbial process, ammonia oxidizing bacteria $(\mathrm{AOB})^{1}$ or archaea $(\mathrm{AOA})^{2}$ oxidize ammonia to nitrite, which is further oxidized by nitrite oxidizing bacteria $(\mathrm{NOB})^{1}$ to nitrate. Besides canonical ammonia and nitrite oxidizing microorganisms, members of the genus Nitrospira have been reported recently to catalyze the complete oxidation pathway from ammonia to nitrate (comammox) $)^{3-5}$. These different groups of nitrifying microorganisms often co-occur in biological filters treating groundwater for drinking water production $^{6-9}$, where they grow attached on the surface or in the porous mineral coatings of the filter media $^{10}$, and co-exist with other microbial taxa with diverse physiologies ${ }^{8,11,12}$. Ammonium removal is sometimes incomplete during biofiltration, causing excessive ammonium concentrations in the finished drinking water. This is problematic, because in systems without disinfection, nitrification during water distribution can result in microbial regrowth (possible growth of pathogens, aesthetic problems) and material corrosion ${ }^{13}$.

Poor nitrification performance can sometimes be resolved by dosing the trace metal copper ${ }^{14}$. Copper is a cofactor for the enzyme ammonia monooxygenase ${ }^{15}$, which catalyzes ammonia oxidation to hydroxylamine. When copper was added at $\mu \mathrm{g} / \mathrm{L}$ level to a biological rapid sand filter that displayed incomplete ammonium removal, nitrification increased and ammonium was removed to $<0.01 \mathrm{mg} \mathrm{NH}_{4}{ }^{+}-$ $\mathrm{N} / \mathrm{L}$ within less than 3 weeks ${ }^{14}$. A further, more comprehensive investigation at 10 groundwater treatment plants showed a consistent effect of copper dosing to remediate poorly nitrifying biofilters ${ }^{16}$. The progressive but rapid increase in nitrification efficiency suggests nitrifier growth stimulated by copper addition. Yet, this has not been examined. If correct, it is possible that such growth would modify the 
59 composition of nitrifiers. Therefore, the present study aimed to answer the following: is copper-induced 60 stimulation of nitrification in biological rapid sand filters associated with an increase in nitrifier density 61 and/or with a change of composition within the nitrifying genera? This question was investigated at three 62 full-scale drinking water treatment plants. MATERIAL AND METHODS

\section{Drinking water treatment plants}

65 The three investigated drinking water treatment plants (DWTPs) are located in Denmark (Holmehave 66 DWTP (VCS Denmark): 55¹7'24.9"N, 10¹1'19.8"E, Nærum DWTP (Novafos, formerly Forsyningen 67 Allerød Rudersdal): 5549'04.5"N, 12³1'24.2"E, and Glostrup DWTP (Glostrup Forsyning): $55^{\circ} 40^{\prime} 02.3^{\prime \prime} \mathrm{N} \mathrm{12} 23^{\prime} 00.1 " \mathrm{E}$ ). Groundwater from anaerobic aquifers is treated through aeration (plate aeration at Holmehave, stairs aeration at Nærum and Glostrup), followed by filtration with single stage, gravity driven, rapid sand filters (0.8-1.4 mm quartz sand at all plants and active depths of $0.6 \mathrm{~m}$ at Nærum, $0.75 \mathrm{~m}$ at Holmehave, and $0.6 \mathrm{~m}$ at Glostrup), and the treated water is distributed without disinfection. Influent water to the filters (Table 1) is relatively high in alkalinity. These treatment plants have experienced incomplete ammonium removal for several years (filter effluent concentrations $>0.01$ $\mathrm{mg} \mathrm{NH}_{4}-\mathrm{N} / \mathrm{L}$; Table 1 and ${ }^{16}$ ) at relatively low hydraulic loading rates of 1.6, 1.9, and $2.5 \mathrm{~m} / \mathrm{h}$ at Nærum, Holmehave and Glostrup DWTP, respectively. 


\section{Table 1. Water quality characteristics at the investigated drinking water treatment plants}

\begin{tabular}{|c|c|c|c|c|c|c|c|c|c|}
\hline & \multicolumn{3}{|c|}{ Holmehave } & \multicolumn{3}{|c|}{ Nærum } & \multicolumn{3}{|c|}{ Glostrup } \\
\hline & influent & eff & ent & influent & & dent & influent & & lent \\
\hline & & $\begin{array}{l}\text { Before } \\
\text { dosing }\end{array}$ & $\begin{array}{l}\text { After } \\
\text { dosing }\end{array}$ & & $\begin{array}{l}\text { Before } \\
\text { dosing }\end{array}$ & $\begin{array}{l}\text { After } \\
\text { dosing }\end{array}$ & & $\begin{array}{l}\text { Before } \\
\text { dosing }\end{array}$ & $\begin{array}{l}\text { After } \\
\text { dosing }\end{array}$ \\
\hline Temp $\left[{ }^{\circ} \mathrm{C}\right]$ & 9.7 & 9.8 & 9.6 & 9.6 & 9.7 & 9.4 & 9.8 & 10.0 & 10.0 \\
\hline $\mathrm{pH}[-]$ & 7.4 & 7.4 & 7.4 & 7.7 & 7.6 & 7.7 & 7.4 & 7.3 & 7.3 \\
\hline $\begin{array}{c}\text { Dissolved } \\
\text { oxygen }\left[\mathrm{mg} \mathrm{L}^{-1}\right]\end{array}$ & 8.9 & 8.8 & 8.6 & 9.8 & 8.9 & 8.4 & 9.2 & 8.7 & 8.2 \\
\hline $\mathrm{NH}_{4}{ }^{+}\left[\mathrm{mg} \mathrm{N} \mathrm{L}^{-1}\right]$ & 0.36 & 0.14 & $<0.01$ & 0.34 & 0.18 & $<0.01$ & 0.42 & 0.17 & $<0.01$ \\
\hline $\mathrm{NO}_{2}^{-}\left[\mathrm{mg} \mathrm{N} \mathrm{L}^{-1}\right]$ & 0.006 & $<0.002$ & $<0.002$ & 0.006 & 0.009 & $<0.002$ & 0.003 & $<0.002$ & $<0.002$ \\
\hline $\mathrm{NO}_{3}{ }^{-}\left[\mathrm{mg} \mathrm{N} \mathrm{L}^{-1}\right]$ & $<0.1$ & 0.22 & 0.40 & 0.33 & 0.51 & 0.69 & $<0.1$ & 0.23 & 0.40 \\
\hline total $\mathrm{Fe}\left[\mathrm{mg} \mathrm{L}^{-1}\right]$ & 1.34 & 0.008 & 0.005 & 2.07 & 0.008 & 0.010 & 1.78 & 0.014 & 0.010 \\
\hline $\mathrm{Mn}\left[\mathrm{mg} \mathrm{L}^{-1}\right]$ & 0.308 & 0.034 & 0.001 & 0.09 & 0.009 & 0.003 & 0.06 & 0.008 & 0.002 \\
\hline $\mathrm{H}_{2} \mathrm{~S}\left[\mathrm{mg} \mathrm{L}^{-1}\right]$ & $<0.02$ & $<0.02$ & $<0.02$ & $<0.02$ & $<0.02$ & $<0.02$ & $<0.02$ & $<0.02$ & $<0.02$ \\
\hline $\mathrm{CH}_{4}\left[\mathrm{mg} \mathrm{L}^{-1}\right]$ & $<0.02 *$ & n.d. & n.d. & $<0.01$ & $<0.01$ & $<0.01$ & $<0.01$ & $<0.01$ & $<0.01$ \\
\hline $\mathrm{PO}_{4}{ }^{3}-\left[\mathrm{mg} \mathrm{P} \mathrm{L}^{-1}\right]$ & 0.066 & $<0.01$ & $<0.01$ & 0.018 & $<0.01$ & $<0.01$ & $<0.01$ & $<0.01$ & $<0.01$ \\
\hline $\begin{array}{c}\text { Alkalinity [mg } \\
\left.\mathrm{HCO}_{3}{ }^{-} \mathrm{L}^{-1}\right]\end{array}$ & 329 & 331 & 322 & 348 & 340 & 341 & 442 & 436 & 434 \\
\hline $\mathrm{Ca}\left[\mathrm{mg} \mathrm{L}^{-1}\right]$ & 103 & 102 & 103 & n.d. & 106 & 105 & 113 & n.d. & n.d. \\
\hline $\mathrm{Cl}^{-}\left[\mathrm{mg} \mathrm{L}^{-1}\right]$ & 25 & 33 & 36 & n.d. & 66 & 65 & 57 & n.d. & n.d. \\
\hline $\mathrm{SO}_{4}^{2-}\left[\mathrm{mg} \mathrm{L}^{-1}\right]$ & 7 & 8 & 9 & n.d. & 43 & 46 & 15 & n.d. & n.d. \\
\hline $\mathrm{NVOC}\left[\mathrm{mg} \mathrm{L}^{-1}\right]$ & 1.5 & 1.4 & 1.4 & n.d. & 1.7 & 1.9 & 1.8 & 1.7 & 1.8 \\
\hline
\end{tabular}

80

81 Water and filter media were sampled from a filter at each DWTP before and after copper dosing, and 82 water samples were also collected during the dosing. At the three plants, copper was dosed through 
83 electrolysis, employing rod-shaped $4 \mathrm{~mm}$ diameter copper electrodes ${ }^{17}$. Nitrification activity of these test

84 filters was evaluated based on the influent and effluent concentrations of ammonium, nitrite and nitrate, 85 and volumetric ammonium removal rates (ARR) were calculated ${ }^{16}$. Additionally, nitrification activity of 86 reference filters, which did not receive dosing, was monitored at all DWTPs.

\section{Water and media sampling}

Influent water was collected from the top of the filters and effluent water from sampling taps. Water from the filters was abstracted from $10 \mathrm{~cm}$ below the surface of the filter by a peristaltic pump (Ole Dich, 101 ACR) at $25 \mathrm{~mL} / \mathrm{min}$ through PTFE tubing inside a stainless-steel probe inserted into the filter at a $45^{\circ}$ angle. Detailed sampling procedure and sample handling and storage are described elsewhere ${ }^{14}$.

Filter media samples were collected from the top $10 \mathrm{~cm}$ of the filters with a stainless steel grab sampler and homogenized. Sub-samples were transferred into sterile $50 \mathrm{~mL}$ PE vials, and transported on ice to the laboratory for processing. All filter media samples were collected at the same time within a filtration cycle (one day after backwash). At Holmehave DWTP, media samples were collected from the test (Cu dosed) filter at six random locations (biological replicates) and from the reference (without $\mathrm{Cu}$ dosing) filter at three locations, just before the start of the copper dosing to the test filter (day 0 ) and after 67 days of dosing. At Glostrup DWTP, samples were collected from the test and the reference filter at six random locations (biological replicates). The test filter (Cu dosed) was sampled 171 days before dosing onset (day -171), just before the start of the copper dosing (day 0) and after 43 days of dosing, and the reference filter (without $\mathrm{Cu}$ dosing) was sampled 171 days before dosing onset (day -171) and just before the start of the copper dosing to the test filter (day 0). Due to operational reasons, approx. $20 \mathrm{~cm}$ of top layer sand were removed from both the test and the reference filter, 90 days before the start of the dosing (day - 
104 90). At Nærum DWTP, samples were collected from the test filter at two locations, just before dosing 105 began (day 0) and after 116 days of dosing.

\section{Chemical parameters}

107 Ammonium,nitrite, phosphate, and hydrogen sulfide were analyzed with colorimetric methods (APHA $4500-\mathrm{NH}_{3} \quad \mathrm{~F}, 4500-\mathrm{NO}_{2}^{-}$ B, 4500-P F, and 4500-S2- D ${ }^{18}$ ) with quantification limits of 0.01 for ammonium and $0.002 \mathrm{mg} \mathrm{N} / \mathrm{L}$ for nitrite. Concentrations of total iron, manganese, calcium, and copper

110 (detection limit of $0.01 \mu \mathrm{g} \mathrm{Cu} / \mathrm{L}$ ) in water samples were determined by ICP-MS - inductively coupled

111 plasma mass spectrometry (Agilent Technologies, 7700 Series ICP-MS), analogous to EPA method $1126020 \mathrm{~A}^{19}$. Nitrate, chloride, and sulfate were analyzed with ion chromatography (APHA 4110-B ${ }^{18}$ ). Non-

113 volatile organic carbon (NVOC) was determined by wet-oxidation method, according to APHA 5310 D

114 18. Methane concentrations were determined in the headspace by gas chromatography (GC). Water phase 115 concentrations under equilibrium conditions were calculated based on the Henry's Law constant. 116 Dissolved oxygen, temperature and $\mathrm{pH}$ were monitored with a hand held meter (WTW, Multi 3430, with 117 FDO ${ }^{\circledR} 925$ and SenTix ${ }^{\circledR} 940$ probes). Total alkalinity (as $\mathrm{HCO}_{3}{ }^{-}$) was determined with titrimetric 118 method (APHA $2330^{18}$ ).

\section{DNA extraction}

120 DNA was extracted from $0.5 \mathrm{~g}$ of wet drained sand using FastDNA ${ }^{\mathrm{TM}}$ spin kit for soil (MP Biomedicals, 121 Solon, OH, USA) according to manufacturer's instructions. DNA was extracted in duplicates from each 122 of the biological replicate sand samples. The DNA concentration was determined using NanoDrop ND1231000 UV-VIS Spectrophotometer (Thermo Fisher Scientific, Waltham, MA, USA) and the extracts were 124 stored at $-20^{\circ} \mathrm{C}$ until further analysis. 


\section{Quantitative PCR, PCR amplification and Illumina Sequencing}

126 Quantitative PCR (qPCR) was used to quantify total Bacteria, ammonia oxidizing bacteria, ammonia

127 oxidizing archaea, nitrite oxidizing bacteria (Nitrospira and Nitrobacter) and comammox Nitrospira

128 (both clades in a single assay, specificity illustrated Figure S8). This was performed with a Chromo4

129 thermocycler using Opticon Monitor version 3 software (BioRad). Each qPCR reaction contained 12.5

$130 \mu \mathrm{L}$ of $2 \mathrm{X}$ iQ SYBR green Supermix (catalog no. 170-8880, Bio-Rad Laboratories), $500 \mathrm{mM}$ primer,

131 DNA template (10 ng), and DNA/RNA free water (Mo Bio Laboratories) to $25 \mu \mathrm{L}$ (ref ${ }^{11}$ ). Primer details,

$132 \mathrm{PCR}$ and qPCR conditions are given in Table S1, S2 and S3. For each sample, $50 \mu \mathrm{L}$ total extracted DNA

133 was sent for 16S rRNA gene PCR amplification, purification and amplicon sequencing using the Illumina

134 MiSeq platform at the DTU Multi Assay Core Center (Kgs. Lyngby, DK). Gene copy numbers from

135 qPCR were converted to cell densities, assuming one 16S rRNA gene per cell of $\mathrm{AOB}^{11}$, one amoA gene

136 per cell of comammox Nitrospira $a^{20}$, and two $n x r B$ genes per cell of Nitrospira ${ }^{20}$. Copy numbers of $16 \mathrm{~S}$

137 rRNA genes for total bacteria were corrected based on the average ribosomal operon number per 138 organism in each sample determined by comparing $16 \mathrm{~S}$ rRNA gene amplicon data to the rnDB 139 database $^{21}$ and calculating the average copy number per sample in $\mathrm{R}$ (script available at

140 https://github.com/ardagulay). Abundance changes caused by copper addition are reported as fold

141 change, calculated as the ratio of the value measured after copper supplementation divided by the value

142 before copper supplementation.

\section{Bioinformatics analysis}

144 Sequences generated as paired FASTQ files were processed using DADA2 (Version - 1.4) ${ }^{22}$. DADA2 145 was used for quality filtering, trimming and de-replicating the reads, inferring sequence variation through 
146 default error model parameters, merging paired reads, removing chimeras, and assigning taxonomy using

147 Silva reference database v123 and custom taxonomy files for nitrifiers. Further analysis on the sequence 148 and taxonomy table generated using DADA2 was performed using Phyloseq R Package (Version 149 1.7.12) $)^{23}$. The Phyloseq extension DESeq2 (Version - 1.16.2) 24 $^{24}$ was used to detect differential relative 150 abundances among the sequence variants or taxa between the two sampling points. This method uses 151 negative binomial generalized linear models and allows adjusting the significance threshold of the Wald 152 test (here 0.05 ) after adjusting the $\mathrm{P}$ values for false discovery rate. Reference 16S rRNA gene sequences

153 for comammox Nitrospira were obtained from GenBank and from re-analysis of amplicon sequencing 154 data from a sand filter for which metagenomic data had shown dominance of comammox ${ }^{8,25}$; see

155 Supplementary Methods, Fig S1 and Table S4. These sequences were then aligned with sequences from 156 this study using ClustalW in MEGAX ${ }^{26,27}$ to generate a maximum of likelihood tree. Sequence variants 157 were putatively assigned to a comammox clade if they were more than $98.5 \%$ similar to one of the 158 comammox Nitrospira reference sequences.

\section{Nucleic Acid Sequences}

160 Raw sequence files were deposited into the Sequence Read Archive at GenBank under the study 161 accession number SRP129820.

\section{RESULTS AND DISCUSSION}

\section{Copper dosing stimulates nitrification}

164 Prior to copper dosing, nitrification had been insufficient for several years in the biological filters of the 165 three DWTPs, resulting in excessive $\mathrm{NH}_{4}{ }^{+}$concentration in the effluent ${ }^{16}$. Just before dosing, the effluent 166 concentrations were $0.14 \mathrm{mg} \mathrm{NH}_{4}{ }^{+}-\mathrm{N} / \mathrm{L}$ at Holmehave, $0.18 \mathrm{mg} \mathrm{NH}_{4}{ }^{+}-\mathrm{N} / \mathrm{L}$ at Nærum, and $0.17 \mathrm{mg} \mathrm{NH}_{4}{ }^{+}-$ 
$167 \mathrm{~N} / \mathrm{L}$ at Glostrup (Table 1). The DWTPs therefore violated the national water quality standard of 0.039 $168 \mathrm{mg} \mathrm{NH}_{4}{ }^{+} \mathrm{N} / \mathrm{L}{ }^{28}$ by a factor of $3.6-4.6$. At Holmehave, the filter removed $0.60 \mathrm{~g} \mathrm{NH}_{4}{ }^{+}-\mathrm{N} / \mathrm{m}^{3}$ filter 169 material $/ \mathrm{h}$ at an ammonium loading rate of $0.95 \mathrm{~g} \mathrm{NH}_{4}{ }^{+}-\mathrm{N} / \mathrm{m}^{3}$ filter material $/ \mathrm{h}$ (Figure 1), corresponding 170 to $63 \%$ removal. At Nærum DWTP, only $44 \%$ of the influent ammonium was removed, where the filter 171 only achieved a removal rate of $0.22 \mathrm{~g} \mathrm{NH}_{4}{ }^{+}-\mathrm{N} / \mathrm{m}^{3} / \mathrm{h}$ when loaded with $0.50 \mathrm{~g} \mathrm{NH}_{4}{ }^{+}-\mathrm{N} / \mathrm{m}^{3} / \mathrm{h}$. At Glostrup 172 DWTP, ammonium loading and removal rates varied slightly (Figure 1), but when loaded with $0.90 \mathrm{~g}$ $173 \mathrm{NH}_{4}{ }^{+}-\mathrm{N} / \mathrm{m}^{3} / \mathrm{h}$ the day before dosing onset, the filter achieved a removal rate of $0.53 \mathrm{~g} \mathrm{NH}_{4}{ }^{+}-\mathrm{N} / \mathrm{m}^{3} / \mathrm{h}$, 174 corresponding to a $59 \%$ removal. These removal rates were low, compared with 3.4 and $5 \mathrm{~g} \mathrm{NH}_{4}{ }^{+}-\mathrm{N} / \mathrm{m}^{3} / \mathrm{h}$ 175 achieved by similar systems ${ }^{6,7}$, albeit operated under higher ammonium loading rates. Nitrite filter effluent concentrations were $<0.002 \mathrm{mg} \mathrm{NO}{ }^{-}-\mathrm{N} / \mathrm{L}$ at Holmehave and Glostrup DWTPs, but were elevated at $0.009 \mathrm{mg} \mathrm{NO}{ }^{-}-\mathrm{N} / \mathrm{L}$ at Nærum (Table 1 and $^{16}$ ) documenting that nitrite breakthrough is sometimes a problem, with a low regulatory standard of $0.003 \mathrm{mg} \mathrm{NO}_{2}^{-}-\mathrm{N} / \mathrm{L}$ at the effluent of DWTPs ${ }^{28}$.
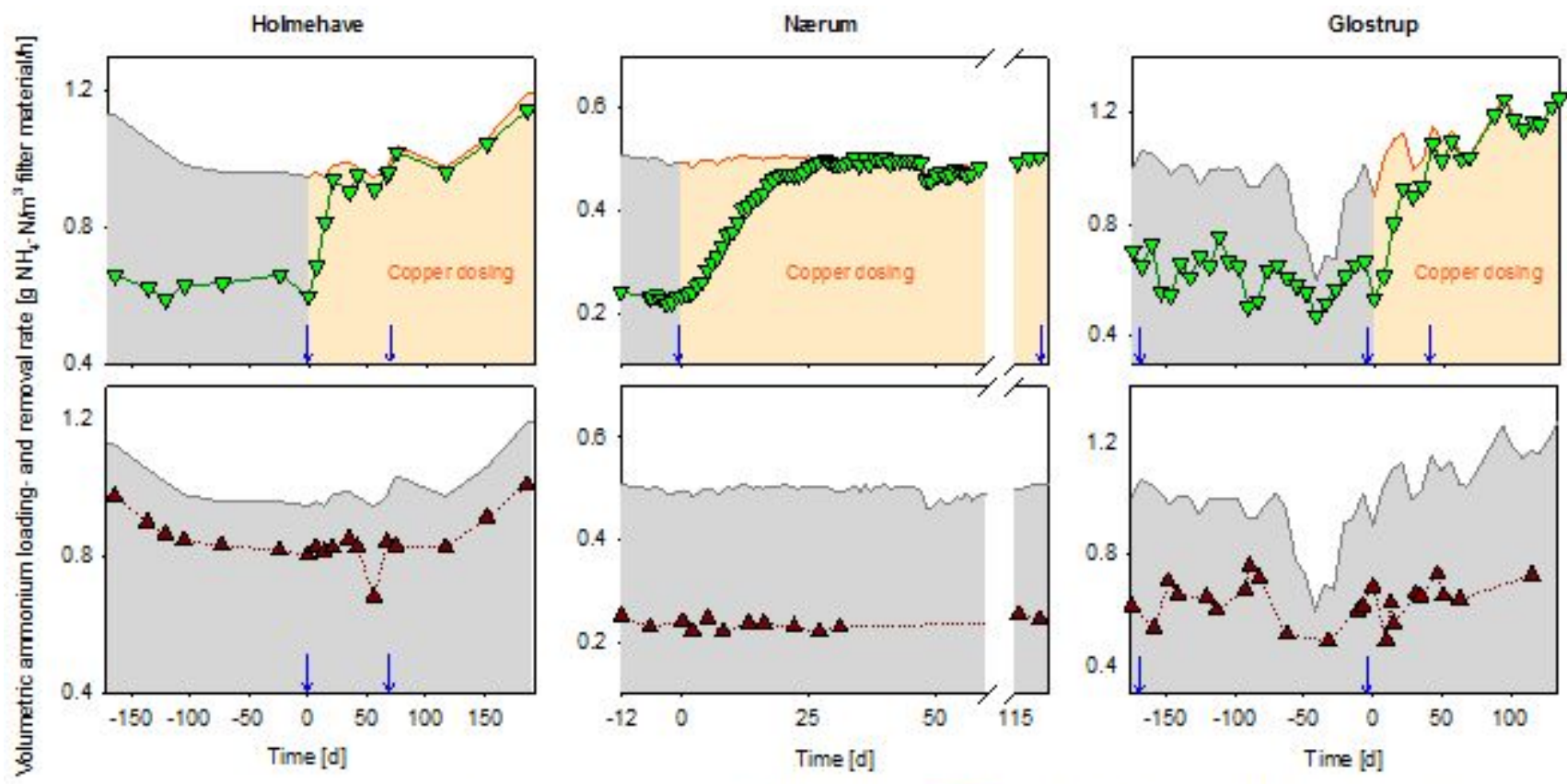
180 Figure 1. Top: Stimulation of ammonium removal rate by copper dosing (start on day 0 ) in the test filters

181 at Holmehave, Nærum, and Glostrup DWTPs, at given ammonium loading rate. Bottom: Absence of

182 improvement in the ammonium removal performance of the reference filters, which did not receive

183 copper. Blue arrows mark filter media sampling. Partly redrawn from ${ }^{16}$.

184 Ammonium removal responded promptly to copper dosing, with increased rates within only a few days

185 for all plants (Figure 1). Effluent concentrations of $<0.01 \mathrm{mg} \mathrm{NH}{ }_{4}^{+}-\mathrm{N} / \mathrm{L}$ were achieved after 22,21 and

18630 days of dosing for Nærum ${ }^{14}$, Holmehave, and Glostrup ${ }^{16}$, respectively. During dosing, the test filters

187 were exposed to average influent dosing concentrations of $0.34 \pm 0.22 \mu \mathrm{g} \mathrm{Cu} / \mathrm{L}$ ( $\mathrm{n}=11$ ) for Nærum, 0.85

$188 \pm 0.24 \mu \mathrm{g} \mathrm{Cu} / \mathrm{L}(\mathrm{n}=8)$ for Holmehave, and $0.70 \pm 0.19 \mu \mathrm{g} \mathrm{Cu} / \mathrm{L}(\mathrm{n}=9)$ for Glostrup. The ammonium

189 removal of the reference filters, which were not subjected to copper dosing, did not change during the

190 investigation at any of the sites (Figure 1). At Holmehave DWTP, approximately $80 \%$ of the ammonium

191 was removed in the reference filter regardless of the ammonium loading rates (Figure 1) while this

192 fraction increased from 63 to approx. 97\% in the test filter in only 3 weeks of dosing (Figure 1). At

193 Nærum and Glostrup DWTPs, the ammonium removal rates achieved by the reference filters were and

194 remained comparable to those achieved by the test filters before dosing (Figure 1). Hence, the increased

195 nitrification in the test filters was a result of the copper dosing. Importantly, additional filter functions

196 such as the removal of iron and manganese were not impaired by the dosing at any plant (Table 1).

\section{Effect of dosing on nitrifier abundance}

198 Microbial densities within the top $10 \mathrm{~cm}$ were quantified by qPCR targeting the 16S rRNA gene for total 199 bacteria and AOB, nxrB for Nitrospira and Nitrobacter, and amoA for AOB, AOA, and comammox 
200 Nitrospira (Figure $2 \&$ Figure S2). The quantified AOA, AOB and comammox are collectively referred 201 to as ammonia oxidizing prokaryotes (AOP).
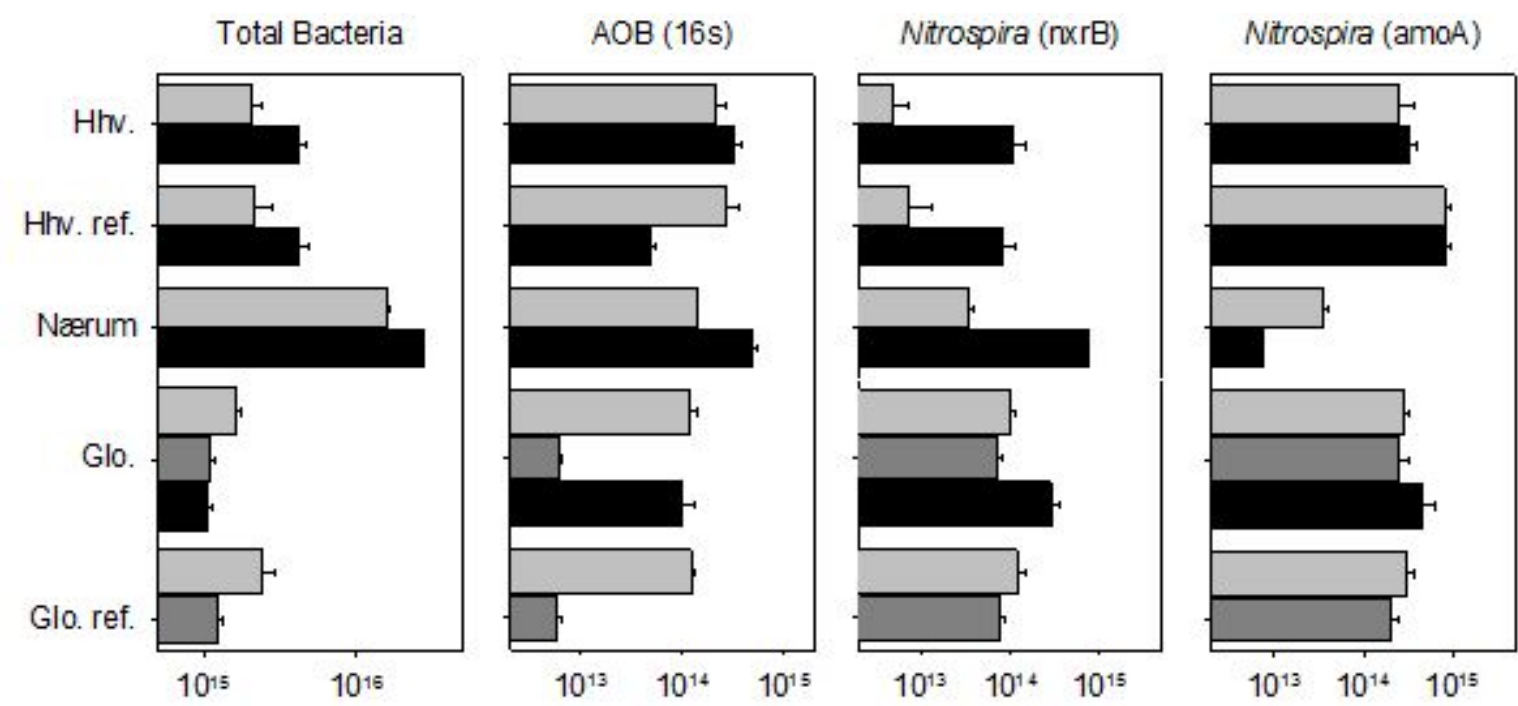

Cell density [cells $\mathrm{m}^{3}$ filter material]

203 Figure 2. Cell densities measured by qPCR before dosing of copper (light grey bars) and 43, 67 or 116 204 days after start of dosing (black bars) to the test filters at Holmehave, Nærum and Glostrup DWTPs. For 205 Glostrup, a second sampling of both filters, right before dosing of the test filter, was conducted (dark 206 grey bars), because the top $20 \mathrm{~cm}$ of the filter material had been removed since the first sampling. The 207 reference filters at Holmehave (Hhv. ref.) and Glostrup (Glo. ref.) did not receive copper dosing. Error 208 bars represent the standard error of the mean from replicate samples.

209 After dosing began, AOB absolute densities estimated from qPCR of the 16S rRNA gene increased in 210 all filters receiving copper, albeit to different degrees (Figure 2). We observed fold changes of 1.5 in 211 Holmehave, of 3.4 in Nærum, and of more than 15 in Glostrup. This large increase in Glostrup is partly 212 due to the fact that $\mathrm{AOB}$ abundance measured just before dosing was low (Figure 2, dark grey bars), 213 most likely because sand from the top of the filter had been removed between the first and second 
214 sampling. The decrease of AOB density after the sand removal suggests some degree of biomass 215 stratification, which has been described previously in such systems ${ }^{9}$. Compared to the abundances of 216 AOB derived from 16S rRNA gene-based qPCR, those measured by the amo $A$ targeted qPCR were 217 between 2 and 3 orders of magnitude lower (Figure S2), which is likely due to the poor coverage of the 218 amo $A$ primers, as reported previously ${ }^{7,29}$. Yet, the two qPCR methods yielded results that matched in 219 their temporal trends (increase vs. decrease in AOB abundance) for both test and reference filters at 220 Holmehave and at Glostrup DWTPs. This was, however, not verified for Nærum DWTP, where AOB 221 abundance increased when measured with 16S rRNA gene-based qPCR, but showed no significant 222 change when quantified with amoA targeted qPCR (Figure S2). AOA densities were close to or below 223 the qPCR quantification limit (10 gene copies per reaction) and were thus under $8 \times 10^{10}$ cells $/ \mathrm{m}^{3}$ filter 224 material (Figure S2), 2 to 4 orders of magnitude lower than previously reported in similar full scale filters 225 with good nitrification peformance 9 . In relative terms, this amounted to only $0.0008-0.007 \%$ of total 226 AOP, and dosing did not change their abundance significantly. Considering that cell specific ammonia 227 oxidation rates of AOA are generally 1 to 2 orders of magnitude lower than for $\mathrm{AOB}^{30}$, the contribution of AOA to ammonium removal in the present study is likely negligible. Some AOA have been suggested to have a higher requirement for copper than $\mathrm{AOB}^{31,32}$ which may contribute to their low relative 230 abundance in these copper limited systems.

231 Application of newly developed qPCR primers targeting amoA of Nitrospira ${ }^{25}$ revealed the presence of 232 comammox Nitrospira at both DWTPs. Before dosing, and compared to AOB (16S rRNA gene), 233 comammox Nitrospira densities were slightly higher (16\%) at Holmehave, and lower (75\%) at Nærum 234 DWTP. Interestingly, compared to before dosing, comammox Nitrospira increased slightly (fold change: 235 1.3) in the filter at Holmehave, and decreased distinctly (fold change: 0.2) at Nærum DWTP (Figure 2). 
236 At Glostrup DWTP, comammox Nitrospira were more abundant than AOB (16S rRNA gene) just before 237 copper dosing was started (Figure 2, dark grey bars), but their increase (1.8 fold) was smaller than that 238 of AOB. Nitrospira $(n x r B)$ densities increased at all three plants after the dosing; however, this was also 239 observed in the reference filter at Holmehave (Figure 2). The melting curve for Nitrobacter nxrB qPCR 240 had multiple peaks and amplicon sequencing yielded no Nitrobacter-related sequences (Nitrobacter data 241 is thus not shown). Therefore, Nitrospira spp. must have been the dominant nitrite oxidizers. Total 242 bacterial density increased significantly in filters dosed with copper at Holmehave and Nærum (p-value 243 of 0.003 for both plants). However, it is difficult to ascribe the increase to copper dosing, as total bacteria 244 also increased in the reference filter at Holmehave, and no significant change was observed in the test 245 filter at Glostrup (Figure 2). Overall, qPCR analyses showed that copper dosing increased the abundance 246 of canonical, betaproteobacterial AOB at all three investigated sites, in stark contrast to the Holmehave 247 reference filter without copper dosing. For comammox Nitrospira, a less pronounced growth was 248 observed at Holmehave and Glostrup and even a decrease in abundance at Nærum DWTP (Figure 2). 249 These differences may originate from the fact that sampling occurred later relative to the beginning of 250 dosing at Nærum than at the other sites.

\section{Effect on relative abundance of nitrifiers assessed at the genus and sequence variant levels}

252 To obtain a deeper and broader insight in the microbial communities, they were subjected to amplicon 253 sequencing of the 16S rRNA gene. After quality filtering, 2,415,214 sequences were distributed among 2542279 sequence variants. Of the total number of sequences, $702,639(\sim 29 \%)$ belonged to 27 sequence 255 variants assigned to the genus Nitrospira and 34,282 $(\sim 1.4 \%)$ to 23 sequence variants assigned to the 256 genus Nitrosomonas. 
257 First, we used the amplicon sequencing information to confirm the effect of copper dosing on the groups 258 targeted by our qPCR assays. The copper dosing did not provoke a drastic change in the microbial 259 composition of the filters (Figure 3). Nitrospira was and remained the dominant genus in all plants 260 (Figure 3, top), which is consistent with previous studies of microbial composition in groundwater-fed 261 rapid sand filters ${ }^{8,25}$. In the reference filters, the relative abundance of both Nitrosomonas and Nitrospira 262 genera remained stable, except for a slight decrease for Nitrosomonas between the two pre-copper dosing 263 samplings in Glostrup (Figure 3, lower panels). In the test filters, however, the relative abundance of 264 Nitrosomonas increased almost 10-fold after copper dosing started (Figure 3, top panels). The relative 265 abundance of Nitrospira, which was initially more than 20 times that of Nitrosomonas, did not show such 266 an increase; in fact, an increase or a decrease was detected depending on the site: modest increase Nærum 267 and Holmehave ( $\mathrm{p}$-value $<0.001$ ), but decrease for Glostrup ( $\mathrm{p}<0.001$ ) (Tables S5, S6, and S7). The only 268 other nitrifiers detected were Nitrotoga $(<1 \%$ of the total reads), which did not significantly respond to 269 copper addition. 


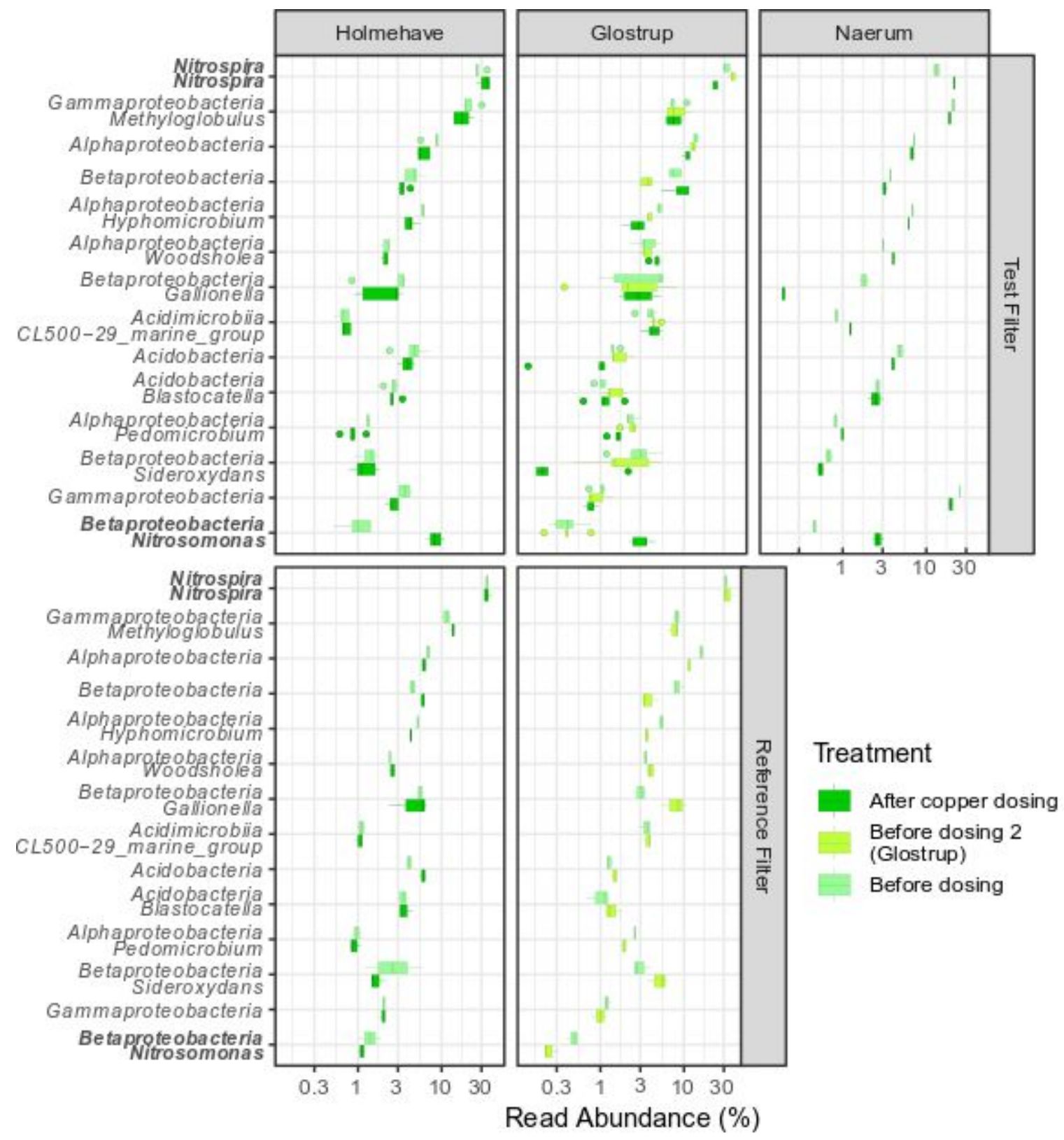

273 Figure 3. Taxonomic distribution of 16S rRNA gene sequences in the copper-dosed and the reference

274 filters. The relative abundances of the 14 most abundant genera are presented. The sequences are grouped 275 according to their assigned genus (labeled as "Class Genus", NA indicates unidentified genera), 276 nitrifying genera are highlight in bold. Box plots are computed from 5 replicate samples for Holmehave 277 and Glostrup test filters, 3 for the reference filters, and 2 for Nærum test filter. Dots represent data points 
278 that lie at least 1.5 interquartile ranges below the first quartile or above the third quartile. For Glostrup, "Before 279 dosing 2" denotes the sample taken just before the onset of dosing, but after sand was removed from the 280 filter.

281 Furthermore, we investigated if copper dosing affected taxa other than nitrifiers. In Holmehave test filter, 282 sampled just two months after initiating dosing, no genera had changed in relative abundance (Figure S3 283 and Table S5), and only a few did in Nærum: Ca. Odyssella and unclassified Acidobacteria increased 284 significantly (fold change $\sim 6$ and 2 , respectively) and Gallionella decreased significantly (fold change 285 0.1); Figure S4 and Table S6). In contrast, the community composition at Glostrup after the onset of 286 copper dosing differed more largely from its previous states, described 214 and 43 days earlier, with respectively 45 and 54 non-nitrifying genera detected as having varied in relative abundance (Figure S5 and Table S7). Many of these have unknown function but several of the genera which decreased in relative abundance were likely involved in the metabolism of sulfur (Sulfurovum, Sulfuricella, Sulfuritalea, Desulfobulbus) or in manganese oxidation (Hyphomicrobium, Pedomicrobium). We could not identify toxicity thresholds for these negatively affected genera in the literature. However, for Escherichia coli, copper concentrations of at least $3.8 \times 10^{5} \mu \mathrm{g} \mathrm{Cu} / \mathrm{L}$ has been reported as inhibiting 293 growth $^{33}$, which is more than five orders of magnitude above the range measured in these filters $(<1 \mu \mathrm{g}$ $\mathrm{Cu} / \mathrm{L}$ ). Therefore, it is highly unlikely that the observed decreases in relative abundance were caused by copper toxicity. These were thus either temporal fluctuations unrelated to the dosing or, more likely, 296 were the result of intensified competition for other nutrients with organisms that benefited from copper dosing. Even if some of these genera could be implicated in important functions such as removal of iron 298 (a likely function of Gallionella ${ }^{8,34}$ ) or of manganese, no deterioration of the effluent water quality was 
299 observed (Table 1), possibly because their activity was compensated by other microbes (via functional 300 redundancy) and/or by abiotic oxidation.

301 To investigate how the microbial composition within the dominant nitrifying genera was affected by 302 copper dosing, we performed a sequence variant-level analysis of the test filters. Eleven sequence 303 variants of Nitrosomonas were detected in more than a single sample, of which two were very abundant 304 at all sites ( $\sim 90 \%$ of all Nitrosomonas reads) (Figure 4$)$. These two sequence variants belong to different 305 branches of Nitrosomonas Cluster 6, with 16S_3168 closely related to Nitrosomonas oligotropha strain 306 Nm45 (97\% identity) and thus putatively assigned to Cluster 6A 35 , while 16S_3167 could not be placed 307 in a subcluster (closest type strain: Nitrosomonas marina strain Nm22 with 95\% identity) (Figure S5). 308 Nitrosomonas 6A members (N. oligotropha and $N$. ureae) are commonly adapted to very low ammonium concentrations (1-5 mM ammonium) with a maximum tolerance to ammonium of 50-200 $\mathrm{mM}^{36}$. They are usually considered as the betaproteobacterial AOB with the highest affinity for ammonium (Ks in the 1.9-4.2 $\mu \mathrm{M}$ range $)^{37}$. The ability of Cluster 6 members to produce ample amount of extracellular polymeric substances (EPS) also make them well adapted to growth at the surface of the filter material ${ }^{38}$.

313 The prevalence of Nitrosomonas cluster 6 observed here is consistent with previous findings in similar 314 biological sand filters for drinking water production, where members of Nitrosomonas cluster 6A 315 (Nitrosomonas sp. Is79A3) and cluster 7 were dominant among the $\mathrm{AOB}^{8}$. The heatmap of Nitrosomonas 316 sequence variants (Figure 4) indicated that copper addition did not markedly modify the composition 317 within this genus, even though only three or four most abundant sequence variants were statistically 318 significantly positively affected in terms of relative abundance within the total community (2.2-3.8 fold 319 across all plants; all adjusted p-values $<5 \times 10^{-5}$ ). This demonstrates that the increase of Nitrosomonas 
was not restricted to a specific type, possibly because of the relative homogeneity of the initial

321 composition (only cluster 6 representatives).

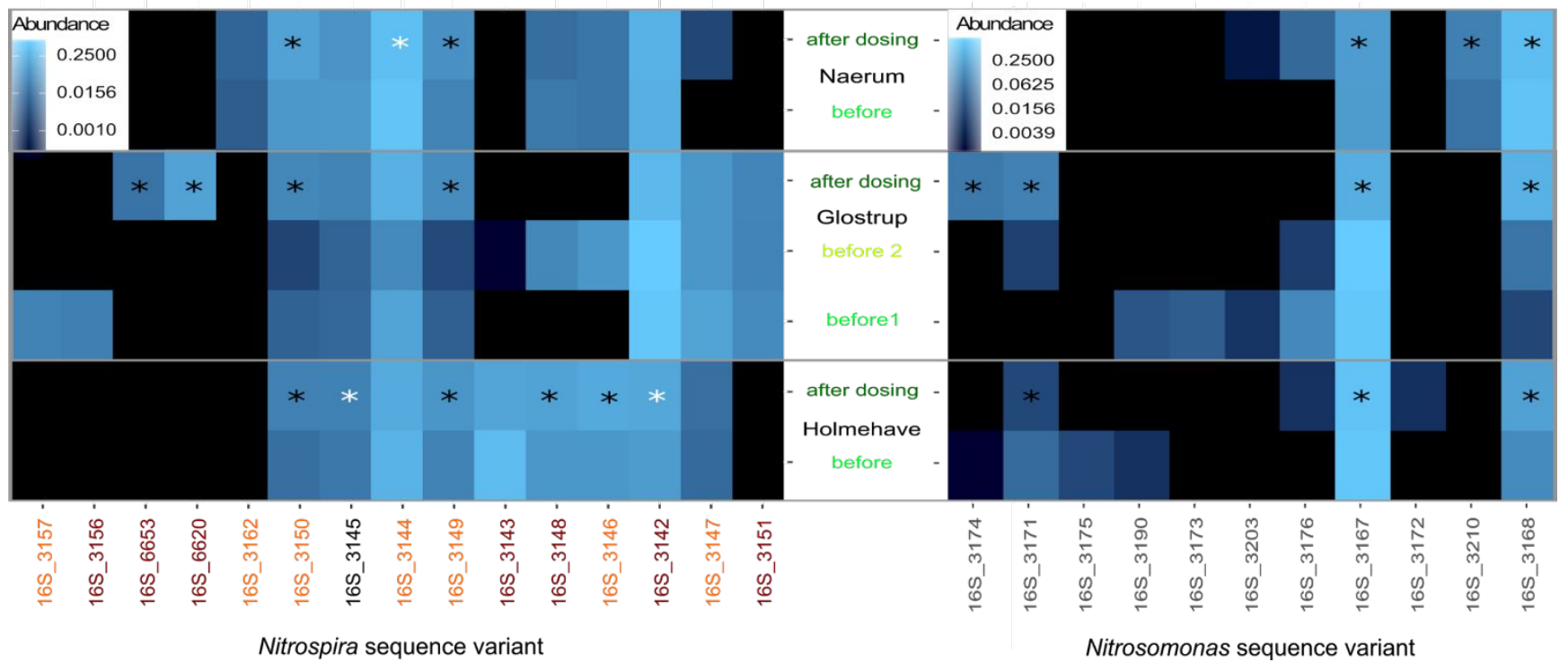

324 Figure 4. Abundance of sequence variants assigned to Nitrospira (left) and Nitrosomonas (right) relative to the total number of sequence variants of each genus for the test filters of three DWTP before and after copper addition, averaged over 2 to 5 replicate samples. Stars denote significant increase in the sequence variant relative abundance upon copper addition (white and back symbols for increase lower or larger 328 than one $\log 2$, respectively). The color of the Nitrospira sequence names indicate their putative 329 classification as canonical NOB (black) or comammox clade A (dark red) or clade B (orange).

330 Considering Nitrospira, 15 sequence variants were detected in more than a single sample (Figure 4), 331 which is relatively low considering the high abundance of this genus. All these variants were assigned to 332 Nitrospira lineage II (Figure S6), a broadly distributed lineage often found in freshwater and in drinking 
333 water distribution systems, known to contain comammox representatives. Comammox Nitrospira do not

334 form a monophyletic group within lineage II, but are instead interspersed with nitrite-oxidizing 335 Nitrospira ${ }^{39,40}$. Therefore, uncertainties are associated with using the 16S rRNA gene as a marker to 336 distinguish comammox from non-comammox (strict NOB) Nitrospira. Nevertheless, based on their close 337 similarity with previously described $16 \mathrm{~S}$ rRNA gene sequences of comammox (always $>98.8 \%$, Figure 338 S6), we propose that eleven of the variants are likely comammox bacteria. These include the two most 339 abundant variants $(\sim 45 \%$ of total Nitrospira), which we tentatively assigned to comammox Clade A (16S_3142) and B (16S_3144). Such a high prevalence of comammox was recently demonstrated or suggested in similar rapid sand filters ${ }^{8,9,25}$ as well as the joint presence of clades A and $B^{25,40}$. Like for Nitrosomonas, the general picture within the genus upon copper supplementation is one of compositional stability (Figure 4), although our statistical analysis detected proliferation at the community level for only some of the dominant variants, most of them putative comammox (six in Holmehave, three in Nærum, and four in Glostrup, all adjusted $\mathrm{p}<0.003)$. Only two $\left(16 \mathrm{~S} \_3149,16 \mathrm{~S} \_3150\right.$, both putative comammox clade B) significantly increased in the three plants, with fold increase in the 2.6-6.1 range.

347 Therefore, the copper induced stimulation of nitrification did not markedly modify the composition 348 within the two most implicated genera, suggesting that this did not constitute a strong differential selective pressure at the sub-genus level. The composition in the three plants for these two genera was very similar down to the sequence variant level, with most of the dominant variants being shared. This probably contributes to their consistent response to copper supplementation.

\section{Contribution of betaproteobacterial $A O B$ and comammox to total $A O P$}


353 To assess the relative contribution of betaproteobacterial AOB and comammox Nitrospira to total 354 ammonia oxidizing prokaryotes (AOP) before and after dosing, estimates of AOB and comammox 355 Nitrospira abundances from targeted qPCR were summed up and their fractions calculated (Figure 5, 356 left). Based on qPCR estimates, the fraction of betaproteobacterial AOB increased from $44 \%$ to $51 \%$ at 357 Holmehave, from 80 to $98 \%$ at Nærum, and from 2 to $18 \%$ at Glostrup, comparing just before ("be2”) 358 and 43 days after dosing onset (Figure 5, left). Based on amplicon sequencing, the initial fraction of 359 comammox Nitrospira was significantly larger at all plants (Figure 5, right). The discrepancy between 360 the results of the two methods may have been caused by an overestimation of AOB abundance by the 361 qPCR targeting the 16S rRNA gene ${ }^{29}$. An in-depth analysis of biases associated with the amoA Nitrospira 362 primers has not been performed, but it is known that the primers present mismatches to Nitrospira amoA 363 genes, thus biases in amplification resulting in over- and/or under-estimation of different comammox 364 Nitrospira likely exist. However, the trend of an increasing fraction of betaproteobacterial AOB with 365 copper dosing was consistent (Figure 5), which means that comammox Nitrospira became relatively less 366 -and canonical ammonia oxidizers relatively more- prevalent within total AOP as a result of the copper 367 dosing. This indicates that once copper limitation was lifted, Nitrosomonas had higher fitness than 368 comammox Nitrospira, at least transitorily. This higher fitness of AOB may be explained by their 369 comparatively higher maximal specific growth rate ${ }^{41-43}$, which should also translate into comparatively 370 higher cell specific ammonia utilization rate. The increased activity of Nitrosomomas was indeed 371 evidenced in Holmehave by the nitritite accumulation which transiently occurred after copper dosing was 372 initiated $^{16}$. By contrast, comammox Nitrospira outcompetition of AOB in copper deficient conditions 373 demonstrates their ability to efficiently compete for copper uptake at low concentration, as proposed 374 based on comparative genomics ${ }^{20}$. In addition, comammox Nitrospira certainly have other traits that 375 make them well adapted to conditions in these rapid sand filters (very high affinity to ammonia, high 
376 yield) as they dominate over Nitrosomonas in the vast majority of the DWTP filters without copper 377 deficiency we surveyed ${ }^{25}$. This is why we do not expect copper dosing to result in a complete change of 378 dominance within the AOP.

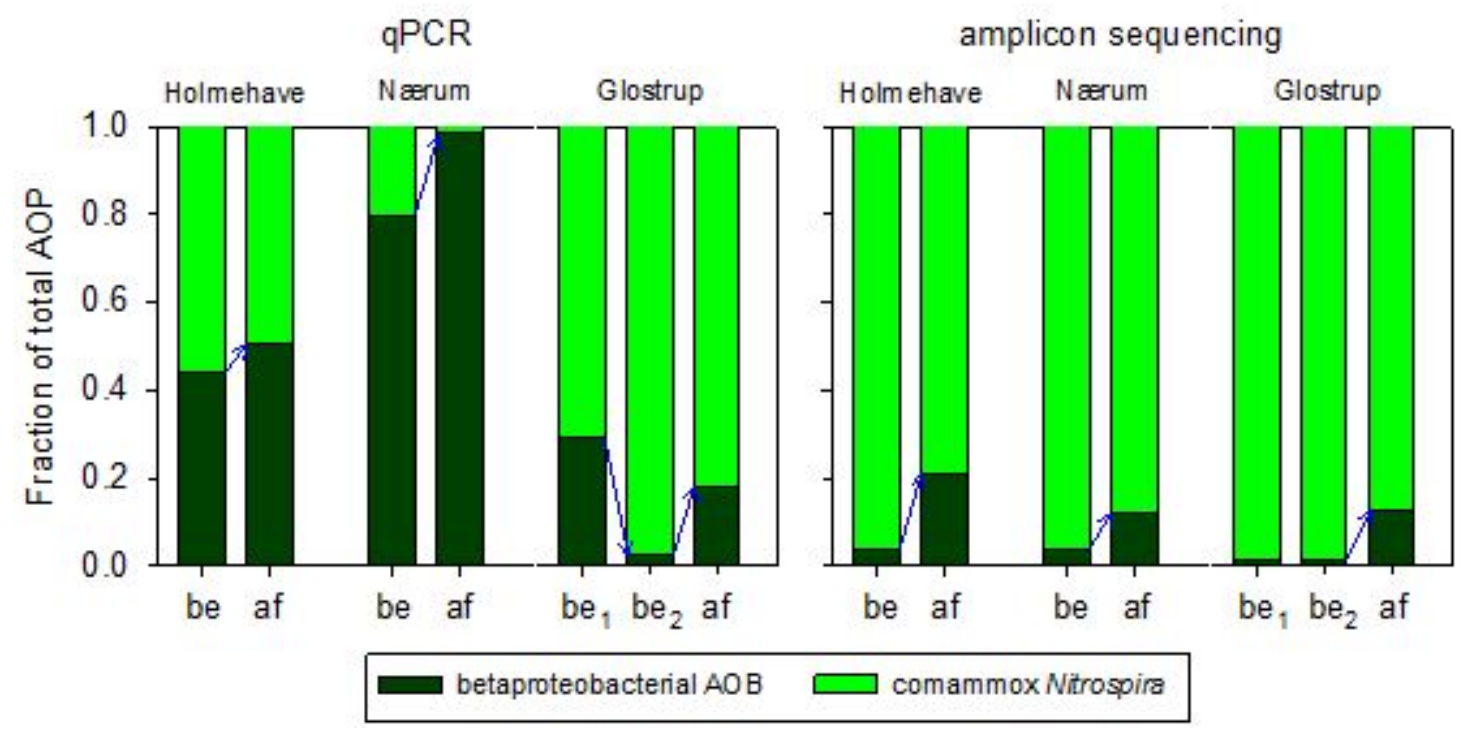

Figure 5 - Effect of copper dosing on the contribution of betaproteobacterial AOB and comammox 381 Nitrospira to total AOP abundance, as estimated with two types of molecular approaches. The qPCR 382 based quantification was performed using 16S rRNA gene (betaproteobacterial AOB) and amoA 383 (comammox Nitrospira). For Glostrup, "be 2 " is the second sample before the onset of dosing, but after 384 sand was removed from the filter.

385 Overall, our study showed that copper-induced stimulation of nitrification in biological rapid sand filters 386 involved changes in nitrifiers abundance. The genus Nitrospira was and remained the most abundant; 387 however, the copper-induced change of Nitrosomonas relative abundance was much higher than for 388 Nitrospira. This proliferation of betaproteobacterial AOB certainly contributed to the rapid increase in ammonium removal. Our finding that copper dosing did not consistently markedly affect the relative 390 abundance of other microbial guilds in the filters is of practical relevance. Taken together, our results 
391 clarify the consequences of copper dosing on copper-deficient rapid sand filters: it consistently stimulates 392 nitrifiers growth and increases the fraction of Nitrosomonas within weeks, but with lasting effect 393 (detected after four months of dosing in Nærum DWTP). This strengthens the notion that the joint 394 contribution of AOB and comammox Nitrospira ensures efficient nitrification in groundwater-fed rapid 395 sand filter for drinking water production.

\section{ACKNOWLEDGMENTS}

397 The authors wish to thank the drinking water utilities at Holmehave DWTP (VCS Denmark),Nærum 398 DWTP (Novafos, formerly Forsyningen Allerød Rudersdal) and Glostrup DWTP (Glostrup Forsyning) 399 for their participation, help and cooperation in this study. Arda Gülay is acknowledged for calculation of 400 the average 16S rRNA copy number per sample for total bacteria. This work was in part supported by 401 MERMAID (an initial training network funded by the People Programme-Marie Skłodowska-Curie 402 Actions- of the European Union's Seventh Framework Programme FP7/2007-2013/ under REA grant 403 agreement no. 607492) and by DTU Environment.

\section{AUTHOR CONTRIBUTIONS}

$405+$ Florian B. Wagner and Vaibhav Diwan contributed equally as first authors.

\section{NOTES}

407 The authors declare no competing financial interest. 
412 (1) Prosser, J. I. Autotrophic Nitrification in Bacteria. In Advances in Microbial Physiology; Rose, A.

H., Tempest,

D. W.,

Eds.;

Academic

Press,

1989.

414 https://doi.org/10.1017/CBO9781107415324.004.

415

(2) Könneke, M.; Bernhard, A. E.; de la Torre, J. R.; Walker, C. B.; Waterbury, J. B.; Stahl, D. A. Isolation of an Autotrophic Ammonia-Oxidizing Marine Archaeon. Nature 2005, 437 (7058), 543-546. https://doi.org/10.1038/nature03911.

Daims, H.; Lebedeva, E. V.; Pjevac, P.; Han, P.; Herbold, C.; Albertsen, M.; Jehmlich, N.; Palatinszky, M.; Vierheilig, J.; Bulaev, A.; Rasmus H. Kirkegaard, R. H.; von Bergen, M.; Rattei, T., Bendinger, B; Nielsen, P. H.; Wagner, M. Complete Nitrification by Nitrospira Bacteria. Nature 2015, 528 (7583). https://doi.org/10.1038/nature16461.

(4) van Kessel, M. A. H. J.; Speth, D. R.; Albertsen, M.; Nielsen, P. H.; Op den Camp, H. J. M.; 423 Kartal, B.; Jetten, M. S. M.; Lücker, S. Complete Nitrification by a Single Microorganism. Nature 2015, 528 (7583), 555-+. https://doi.org/10.1038/nature16459.

(5) Pinto, A. J.; Marcus, D. N.; Ijaz, U. Z.; Bautista-de lose Santos, Q. M.; Dick, G. J.; Raskin, L. Metagenomic Evidence for the Presence of Comammox Nitrospira -Like Bacteria in a Drinking Water System. mSphere 2015, 1 (1), e00054-15. https://doi.org/10.1128/mSphere.00054-15. 
(6) de Vet, W. W. J. M.; Kleerebezem, R.; van der Wielen, P. W. J. J.; Rietveld, L. C.; van Loosdrecht, M. C. M. Assessment of Nitrification in Groundwater Filters for Drinking Water Production by QPCR and Activity Measurement. Water Res. 2011, 45 (13), 4008-4018. https://doi.org/10.1016/j.watres.2011.05.005.

(7) Lee, C. O.; Boe-Hansen, R.; Musovic, S.; Smets, B.; Albrechtsen, H. J.; Binning, P. Effects of Dynamic Operating Conditions on Nitrification in Biological Rapid Sand Filters for Drinking Water Treatment. Water Res. 2014, 64, 226-236. https://doi.org/10.1016/j.watres.2014.07.001.

(8) Palomo, A.; Jane Fowler, S.; Gülay, A.; Rasmussen, S.; Sicheritz-Ponten, T.; Smets, B. F. Metagenomic Analysis of Rapid Gravity Sand Filter Microbial Communities Suggests Novel Physiology of Nitrospira Spp. ISME J. 2016, 10 (11), 2569-2581. https://doi.org/10.1038/ismej.2016.63.

(9) Tatari, K.; Musovic, S.; Gülay, A.; Dechesne, A.; Albrechtsen, H.-J.; Smets, B. F. Density and Distribution of Nitrifying Guilds in Rapid Sand Filters for Drinking Water Production: Dominance of Nitrospira Spp. Water Res. 2017, 127, 239-248. https://doi.org/10.1016/j.watres.2017.10.023.

(10) Gülay, A.; Tatari, K.; Musovic, S.; Mateiu, R. V.; Albrechtsen, H. J.; Smets, B. F. Internal Porosity of Mineral Coating Supports Microbial Activity in Rapid Sand Filters for Groundwater Treatment. Appl. Environ. Microbiol. 2014, 80 (22), 7010-7020. https://doi.org/10.1128/AEM.01959-14.

(11) Gülay, A.; Musovic, S.; Alberchtsen, H. J.; Al-Soud, W. A.; Sørensen, S.; Smets, B. F. Ecological Patterns, Diversity and Core Taxa of Microbial Communities in Groundwater- Fed Rapid Gravity Filters. ISME J. 2016, 1-14. https://doi.org/10.1038/ismej.2016.16. 
448 (12) Albers, C. N.; Ellegaard-Jensen, L.; Harder, C. B.; Rosendahl, S.; Knudsen, B. E.; Ekelund, F.; 449 Aamand, J. Groundwater Chemistry Determines the Prokaryotic Community Structure of 450 451 Waterworks Sand Filters. Environ. Sci. Technol. 2015, 49 (2), 839-846. https://doi.org/10.1021/es5046452.

452

453

454 455

456

457 458

459

460

461

462

463

464 465

466

467

(13) van der Kooij, D. Biological Stability: A Multidimensional Quality Aspect of Treated Water. Water. Air. Soil Pollut. 2000, 123 (1), 25-34. https://doi.org/Doi 10.1023/A:1005288720291.

(14) Wagner, F. B.; Nielsen, P. B.; Boe-Hansen, R.; Albrechtsen, H. J. Copper Deficiency Can Limit Nitrification in Biological Rapid Sand Filters for Drinking Water Production. Water Res. 2016, 95, 280-288. https://doi.org/10.1016/j.watres.2016.03.025.

(15) Sayavedra-soto, L. a; Arp, D. Ammonia-Oxidizing Bacteria: Their Biochemistry and Molecular Biology. In Nitrification; 2011. https://doi.org/10.1002/9781118143391.

(16) Wagner, F. B.; Nielsen, P. B.; Boe-Hansen, R.; Albrechtsen, H.-J. Remediation of Incomplete Nitrification and Capacity Increase of Biofilters at Different Drinking Water Treatment Plants through Copper Dosing. Water Res. 2018, 132, $\quad 42-51$. https://doi.org/10.1016/j.watres.2017.12.061.

(17) Albrechtsen, H.-J.; Wagner, F. B.; Nielsen, P. B.; Boe-Hansen, R.; Fischer, E. V. Apparatus Comprising Trace Element Dosage and Method for Treating Raw Water in Biofilter. Patent application. Patent number: WO2015132283, September 2015.

(18) APHA; AWWA; WEF. Standard Methods for the Examination of Water and Wastewater, 21st ed.; Eaton, A. D., Clesceri, L. S., Rice, E. W., Greenberg, A. E., Eds.; American Public Health 
Association: Washington, DC, 2005; Vol. 21st ed. https://doi.org/10.2105/AJPH.51.6.940-a.

469

470

471

472

473

474

475

476

477

478

479

480

481

482

483

484

485

486

487

(19) USEPA. Inductively Coupled Plasma-Mass Spectometry, EPA 6020A. USEPA Off. Res. Dev. Washingt. 2007.

(20) Palomo, A.; Pedersen, A. G.; Fowler, S. J.; Dechesne, A.; Sicheritz-Pontén, T.; Smets, B. F. Comparative Genomics Sheds Light on Niche Differentiation and the Evolutionary History of Comammox Nitrospira. ISME J. 2018, 12 (7), 1779-1793. https://doi.org/10.1038/s41396-0180083-3.

(21) Stoddard, S. F.; Smith, B. J.; Hein, R.; Roller, B. R. K.; Schmidt, T. M. RrnDB: Improved Tools for Interpreting RRNA Gene Abundance in Bacteria and Archaea and a New Foundation for Future Development. Nucleic Acids Res. 2014, 43 (D1), D593-D598. https://doi.org/10.1093/nar/gku1201.

(22) Callahan, B. J.; McMurdie, P. J.; Rosen, M. J.; Han, A. W.; Johnson, A. J. A.; Holmes, S. P. DADA2: High-Resolution Sample Inference from Illumina Amplicon Data. Nat. Methods 2016, 13 (7), 581-583. https://doi.org/10.1038/nmeth.3869.

(23) McMurdie, P. J.; Holmes, S. Phyloseq: An R Package for Reproducible Interactive Analysis and Graphics of Microbiome Census Data. PLoS One 2013, 8 (4), e61217. https://doi.org/10.1371/journal.pone.0061217.

(24) Love, M. I.; Huber, W.; Anders, S. Moderated Estimation of Fold Change and Dispersion for RNA-Seq Data with DESeq2. Genome Biol. 2014, 15 (12), 550. https://doi.org/10.1186/s13059014-0550-8. 
(25) Fowler, S. J.; Palomo, A.; Dechesne, A.; Mines, P. D.; Smets, B. F. Comammox Nitrospira Are Abundant Ammonia Oxidizers in Diverse Groundwater-Fed Rapid Sand Filter Communities. Environ. Microbiol. 2018, 20 (3), 1002-1015. https://doi.org/10.1111/1462-2920.14033.

(26) Larkin, M. A.; Blackshields, G.; Brown, N. P.; Chenna, R.; Mcgettigan, P. A.; Mcwilliam, H.; Valentin, F.; Wallace, I. M.; Wilm, A.; Lopez, R.; Thompson J. D.; Gibson, T. J.; Higgins, D. G. Clustal W and Clustal X Version 2.0. 2007, $23 \quad$ (21), 2947-2948. https://doi.org/10.1093/bioinformatics/btm404.

(27) Kumar, S.; Stecher, G.; Li, M.; Knyaz, C.; Tamura, K. MEGA X: Molecular Evolutionary Genetics Analysis across Computing Platforms. Mol. Biol. Evol. 2018, 35 (6), 1547-1549. https://doi.org/10.1093/molbev/msy096.

(28) Ministry of Environment and Food of Denmark. Statuary Order on Water Quality and Surveillence of Water Supply Facilities, in Danish (Bekendtgørelse Om Vandkvalitet Og Tilsyn Med Vandforsyningsanlaeg); Ressortministerium: Miljø- og Fødevareministeriet, Administrerende myndighed: Naturstyrelsen, 2017; p BEK nr 802 af 01/06/2016 (Gældende).

(29) Dechesne, A.; Musovic, S.; Palomo, A.; Diwan, V.; Smets, B. F. Underestimation of AmmoniaOxidizing Bacteria Abundance by Amplification Bias in AmoA-Targeted QPCR. Microb. Biotechnol. 2016, 9 (4), 519-524. https://doi.org/10.1111/1751-7915.12366.

(30) Prosser, J. I.; Nicol, G. W. Archaeal and Bacterial Ammonia-Oxidisers in Soil: The Quest for Niche Specialisation and Differentiation. Trends Microbiol. 2012, 20 (11), 523-531. https://doi.org/10.1016/j.tim.2012.08.001. 
508 (31) Walker, C. B.; de la Torre, J. R.; Klotz, M. G.; Urakawa, H.; Pinel, N.; Arp, D. J.; Brochier509 Armanet, C.; Chain, P. S. G.; Chan, P. P.; Gollabgir, A.; Hemp, J.; Hugler, M.; Karr, E. A; . Konneke, M.; Shin, M.; Lawton, T. J.; Lowe, T.; Martens-Habbena, W.; Sayavedra-Soto, L.; Lang,

511

512 513

514

515

516

517

A.D.; Sievert, S. M.; Rosenzweig, A. C.; Manning, G.; Stahl, D. A. Nitrosopumilus Maritimus Genome Reveals Unique Mechanisms for Nitrification and Autotrophy in Globally Distributed Marine Crenarchaea. Proc. Natl. Acad. Sci. 2010, 107 (19), 8818-8823. https://doi.org/10.1073/pnas.0913533107.

(32) Amin, S. A.; Moffett, J. W.; Martens-Habbena, W.; Jacquot, J. E.; Han, Y.; Devol, A.; Ingalls, A. E.; Stahl, D. A.; Armbrust, E. V. Copper Requirements of the Ammonia-Oxidizing Archaeon Nitrosopumilus Maritimus SCM1 and Implications for Nitrification in the Marine Environment. Limnol. Oceanogr. 2013, 58 (6), 2037-2045. https://doi.org/10.4319/1o.2013.58.6.2037.

(33) Grey, B.; Steck, T. R. Concentrations of Copper Thought To Be Toxic to Escherichia Coli Can Induce the Viable but Nonculturable Condition. Appl. Environ. Microbiol. 2001, 67 (11), 53255327. https://doi.org/10.1128/AEM.67.11.5325.

(34) Gülay, A.; Çekiç, Y.; Musovic, S.; Albrechtsen, H.-J.; Smets, B. F. Diversity of Iron Oxidizers in Groundwater-Fed Rapid Sand Filters: Evidence of Fe(II)-Dependent Growth by Curvibacter and Undibacterium Spp. Front. Microbiol. 2018, 9, 2808. https://doi.org/10.3389/fmicb.2018.02808.

(35) Norton, J. M. Diversity and Environmental Distribution of Ammonia-Oxidizing Bacteria. In Nitrification; Ward, B. B., Arp, D., Klotz, M. G., Eds.; American Society of Microbiology: Washington, DC, 2011; pp 39-55. https://doi.org/10.1128/9781555817145.ch3.

(36) Prosser, J. I.; Head, I. M.; Stein, L. Y. The Family Nitrosomonadaceae. In The Prokaryotes: 
Alphaproteobacteria and Betaproteobacteria; Rosenberg, E., Ed.; 2013; pp 1-1012. https://doi.org/10.1007/978-3-642-30197-1.

531

532

533

534

535

536

537

538

539

540

541

542

543

544

545

546

547

548

549

(37) Koops, H. P.; Bottcher, B.; Moller, U. C.; Pommerening-Roser, A.; Stehr, G. Classification of Eight New Species of Ammonia-Oxidizing Bacteria: Nitrosomonas Communis Sp. Nov., Nitrosomonas Ureae Sp. Nov., Nitrosomonas Aestuarii Sp. Nov., Nitrosomonas Marina Sp. Nov., Nitrosomonas Nitrosa Sp. Nov., Nitrosomonas Eutropha Sp. Nov., Nitrosomonas Oligotropha Sp. Nov. and Nitrosomonas Halophila Sp. Nov. J. Gen. Microbiol. 1991, 137 (7), 1689-1699. https://doi.org/10.1099/00221287-137-7-1689.

(38) Stehr, G.; Böttcher, B.; Dittberner, P.; Rath, G.; Koops, H. P. The Ammonia-Oxidizing Nitrifying Population of the River Elbe Estuary. FEMS Microbiol. Ecol. 1995, 17 (3), 177-186. https://doi.org/10.1016/0168-6496(95)00022-3.

(39) Pjevac, P.; Schauberger, C.; Poghosyan, L.; Herbold, C. W.; van Kessel, M. A. H. J.; Daebeler, A.; Steinberger, M.; Jetten, M. S. M.; Lücker, S.; Wagner, M.; Daims, H. AmoA-Targeted Polymerase Chain Reaction Primers for the Specific Detection and Quantification of Comammox Nitrospira in the Environment. Front. Microbiol. 2017, 8, 1508. https://doi.org/10.3389/fmicb.2017.01508.

(40) Palomo, A.; Dechesne, A.; Smets, B. F. Genomic Profiling of Nitrospira Species Reveals Ecological Success of Comammox Nitrospira. bioRxiv 2019, 612226. https://doi.org/10.1101/612226.

(41) Costa, E.; Pérez, J.; Kreft, J.-U. U.; Perez, J. Why Is Metabolic Labour Divided in Nitrification? Trends Microbiol. 2006, 14 (5), 213-219. https://doi.org/10.1016/j.tim.2006.03.006. 
550 (42) Lawson, C. E.; Lücker, S. Complete Ammonia Oxidation: An Important Control on Nitrification 551 in Engineered Ecosystems? Curr. Opin. Biotechnol. 2018, 50, 158-165. https://doi.org/10.1016/j.copbio.2018.01.015.

(43) Kits, K. D.; Sedlacek, C. J.; Lebedeva, E. V.; Han, P.; Bulaev, A.; Pjevac, P.; Daebeler, A.; Romano, S.; Albertsen, M.; Stein, L. Y.; Daims, H. ; Wagner, M. Kinetic Analysis of a Complete Nitrifier Reveals an Oligotrophic Lifestyle. Nature 2017, 549 (7671), 269-272. https://doi.org/10.1038/nature23679. 


\section{$560 \quad$ SUPPORTING INFORMATION}

561 Table S1. Primer and targeted gene used for qPCR and PCR amplification for sequencing.

562 Table S2. qPCR and PCR conditions.

563 Table S3. Reagent concentrations and volumes for a single PCR reaction.

564 Table S4. Result of the matching of Nitrospira comammox MAG to their putative 16Sr RNA gene partial sequence 565 for Islevbro rapid sand filter.

566 Table S5. List of the genera that significantly responded to copper dosing at the Holmehave test filter.

567 Table S6. List of the genera that significantly responded to copper dosing at the Nærum test filter.

568 Table S7. List of the genera that significantly changed abundance between initial and the final sampling at the 569 Glostrup test filter

570 Figure S1. Correlation of the relative of abundance Nitrospira phylotypes as estimated by amplicon sequencing 571 and by metagenomic sequencing and MAG reconstruction in Islevbro rapid sand filter.

572 Figure S2. Cell density measured by qPCR before and after dosing of copper in the test filters at Holmehave 573 Nærum, and Glostrup DWTPs.

574 Figure S3. Taxonomic distribution of 16S rRNA gene sequences for the 50 most abundant genera before and after 575 copper dosing in the test filter at Holmehave DWTP.

576 Figure S4. Taxonomic distribution of 16S rRNA gene sequences for the 50 most abundant genera before and 577 after copper in the test filter at Naerum DWTP. 
578 Figure S5. Taxonomic distribution of 16S rRNA gene sequences for the 50 most abundant genera before and 579 after copper dosing in the test filter at Glostrup DWTPs.

580 Figure S6. Evolutionary relationships of AOB sequence variants from this study to reference Cluster 6 AOB.

581 Figure S7. Evolutionary relationships of Nitrospira sequence variants from this study to reference Nitrospira.

582 Figure S8. Gel electrophoresis of PCR products from the PCR targeting comammox Nitrospira amoA from 583 DNA extracted from DWTPs 
Stimulation of $\mathrm{NH}_{4}^{+}$ relage 35 E $\mid$ | in drinking water biofilters

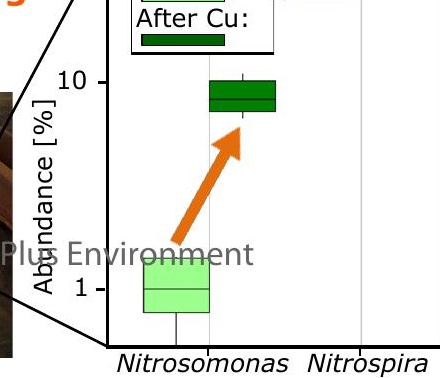

